\title{
Sesame Lignans Increase Sympathetic Nerve Activity and Blood Flow in Rat Skeletal Muscles
}

\author{
Kahori EGAWA $^{1}$, Yuko HORII ${ }^{2}$, Yoshiko MISONOU ${ }^{2}$, Izumi YAMASAKI ${ }^{1}$, Daisuke \\ TAKEMOTO $^{1}$, Yoshiko ONO ${ }^{1}$, Tomohiro ROGI ${ }^{1}$, Hiroshi SHIBATA ${ }^{1}$, Katsuya NAGAI ${ }^{2}$ \\ ${ }^{1}$ Institute for Health Care Science, Suntory Wellness, Ltd., Seikadai, Seika-cho, Soraku-gun, Kyoto, \\ Japan, ${ }^{2}$ ANBAS Corporation, Toyosaki Kita-ku, Osaka, Japan
}

Received August 6, 2019

Accepted January 28, 2020

Epub Ahead of Print March 23, 2020

\begin{abstract}
Summary
Beneficial effects of sesame lignans, especially antioxidative effects, have been widely reported; however, its potential effects on autonomic nerves have not yet been investigated. Therefore, the current study aimed to investigate the effect of sesame lignans on the autonomic nervous system. The sympathetic nerve activity in rat skeletal muscle was measured using electrophysiological approaches, with blood flow determined using the laser Doppler method. Sesame lignans were administered intragastrically at 2 and $20 \mathrm{mg} / \mathrm{kg}$, and after $60 \mathrm{~min}$, the sympathetic nerve activity was observed to increase by $45.2 \%$ and $66.1 \%$, respectively. A significant increase in blood flow (39.6\%) was also observed for the $20-\mathrm{mg} / \mathrm{kg}$ dose when measured at $55 \mathrm{~min}$ after administration. These sympathomimetic effects were completely prevented by subdiaphragmatic vagotomy, and the increase in blood flow was eliminated in the presence of the $\beta 2$-adrenergic receptor inhibitor butoxamine. Thus, it is proposed that sesame lignans can increase the blood flow of skeletal muscle, possibly by exciting sympathetic nerve activity through the afferent vagal nerve.
\end{abstract}

\section{Key words}

Sesamin • Episesamin • Sesame Lignans • Autonomic nerve • Blood flow

\section{Corresponding author}

Katsuya Nagai, ANBAS Corporation, 4-12-10 Toyosaki Kita-ku, Osaka 531-0072, Japan. E-mail: knagai@anbas.co.jp

\section{Introduction}

Sesame (Sesamum indicum L.) seeds have been consumed to maintain health since ancient times.
Sesamin is the major lignan in sesame seeds and oils. In the process of refining sesame oil, roughly half of the sesamin has been found to isomerize to its stereoisomer episesamin (Fukuda et al. 1986). Sesame lignans (sesamin and episesamin) exert various health effects via their functional properties, such as anti-oxidative (Nakai et al. 2003, Ikeda et al. 2003, Kiso 2004), antihypertensive (Matsumura et al. 1995, Kita et al. 1995, Miyawaki et al. 2009), and anti-hyperglycemic properties (Hong et al. 2013, Ide et al. 2012). A recent study has shown that the antioxidant effect of sesame lignans likely suppresses a decline in exercise performance by maintaining mitochondrial function (Takada et al. 2015). Furthermore, we have previously shown that the supplementation of sesame lignans with vitamin E can improve the subjective status of fatigue and the antioxidative capacity in healthy humans with feelings of daily fatigue (Takemoto et al. 2015).

The autonomic nervous system consists of nerves that automatically respond to internal and external stimuli and transmit signals to maintain the homeostasis of vital functions, such as blood pressure, respiration, body temperature and heart rate. Additionally, the autonomic nervous system co-ordinates organ function throughout the body by balancing the activity of sympathetic and parasympathetic nerves. Aging, stress and fatigue cause a reduction and an imbalance in the activity of sympathetic and parasympathetic nerves (Stewart 2000, Amano et al. 2005, Amano et al. 2006, Yukishita et al. 2010, Mizuno et al. 2011). Each organ can also individually regulate its response to autonomic 
nervous system inputs. Generally, $\alpha 1$ - adrenergic receptor is expressed in each organ, and stimulation of sympathetic nerves causes blood vessels to contract, resulting in decrease of blood flow. On the other hand, sympathetic nerve stimulation of the skeletal muscle causes vasodilation of the arterioles and increases blood flow to the skeletal muscles via $\beta 2$-adrenergic receptor (Ganong 2005, Marieb and Hoehn 2008). Actually, we have previously reported that an intraduodenal administration of small amount $(1 \mu \mathrm{g})$ of L-carnosine stimulated the sympathetic nerve innervating the skeletal muscle, increased the skeletal muscle blood flow and intravenous administration of propranolol, an inhibitor of $\beta 2$-adrenergic receptor, eliminated this blood flow increase in rats (Horii et al. 2015). Furthermore, olfactory stimulation with the scent of lavender oil stimulated the sympathetic nerve innervating the skeletal muscle, elevated the skeletal muscle blood flow and this blood flow increase disappeared after intravenous administration of butoxamine, a $\beta 2$-adrenergic receptor inhibitor, in rats (Nagai et al. 2018).

Recently, it has been suggested that the intake of several food ingredients can affect organs and tissues by stimulating autonomic nerve activity, resulting in various physiological changes. For example, intraduodenal administration of culture supernatants from the Lactobacillus pentosus strain S-PT84 has been reported to excite the sympathetic nerve innervating the brown adipose tissue and increase thermogenesis (Beppu et al. 2012). Flavan-3-ol is known to have various effects, and the enhancing energy expenditure can be eliminated by inhibiting autonomic nerves (Osakabe and Terao 2018, Kamio et al. 2016). These examples indicate that the mechanism of modulating the autonomic nervous system is important for a number of food ingredients. Although known effects of sesame lignans include lowering high blood pressure, lowering blood glucose, and alleviating fatigue, the specific actions of sesame lignans on the autonomic nervous system are unknown.

The aim of this study was to directly investigate whether sesame lignans affect skeletal muscle sympathetic nerve activity (SNA) and blood flow in rats following intragastric administration.

\section{Materials and Methods}

\section{Materials used}

Sesame lignans [sesamin and episesamin (SE), 1:1 ratio] were purchased from Takemoto Oil \& Fat Co., Ltd. (Aichi, Japan). Olive oil was purchased from
Nakarai Tesque, Inc. (Kyoto, Japan), butoxamine (butoxamine hydrochloride) was purchased from SigmaAldrich (MO, USA), and urethane was purchased from Tokyo Chemical Industry Co., Ltd. (Tokyo, Japan).

\section{Animals}

Male Wistar rats (Kiwa Laboratory Animals, Co., Ltd., Wakayama, Japan; weight, approximately $300 \mathrm{~g}$; age, 9 weeks) were used in all studies. The rats were acclimated to the environment for at least 1 week before the experiments. The animals were housed individually in a room maintained at $24 \pm 1{ }^{\circ} \mathrm{C}$ and lighted daily for 12 h (08:00-20:00 h). Food (MF; Oriental Yeast Co., Ltd., Tokyo, Japan) and water were available ad libitum.

All protocols for animal procedures were approved by the Institutional Animal Care and Use Committee of ANBAS Corporation and the Ethics Committee of Animal Experiment of Suntory in accordance with the Internal Regulations on Animal Experiments at ANBAS Corporation and Suntory Holdings Limited, which are based on the Law for the Humane Treatment and Management of Animals (Law No. 105, 1 October 1973, as amended on 30 May 2014).

\section{General animal preparation}

On the day of the experiments, the rats were made to fast for $3 \mathrm{~h}$ before the stomach and the cervical vein were cannulated under urethane anesthesia $(1 \mathrm{~g} / \mathrm{kg}$ body weight). A tracheal cannula was inserted to ensure respiration. In all experiments, rats were placed in a stereotaxic apparatus, and the body temperature was maintained at $37 \pm 0.5^{\circ} \mathrm{C}$ using a heating pad.

\section{Measurement of skeletal muscle SNA}

Skeletal muscle SNA was measured as described previously (Horii et al. 2015). In brief, after cannulation, a longitudinal incision was made in the middle of the left femoral region. The sympathetic nerve, which innervates the vastus medialis of the quadriceps femoris muscle, was exposed and hooked up to a pair of silver wire electrodes with an ER-1 Differential Extracellular Amplifier (Cygnus Technology Inc., PA, USA). After stabilization of the rat for $1.5 \mathrm{~h}$, either vehicle $(0.5-\mathrm{ml}$ olive oil, control group) or SE (2 or $20 \mathrm{mg} / \mathrm{kg}$ in $0.5-\mathrm{ml}$ olive oil) was administered through the stomach cannula. Muscle SNA was then recorded for $60 \mathrm{~min}$ (TEC-1 Event Counter; Dagon Corporation, MN, USA), with electrical changes amplified and monitored using an oscilloscope (SS-7802A; Iwatsu Test Instruments Corporation, Tokyo, 
Japan). The raw SNA data was converted to standard spikes using a window discriminator (WD2; Dagan Corporation, MN, USA) to separate the discharges from the electrical background noise. The data conversion from analog to digital format and their recordings were performed as described previously (Tanida et al. 2005). SNA was analyzed by sampling spike frequency every $5 \mathrm{sec}$, then averaging across $5 \mathrm{~min}$ intervals. The averaged signal 5 min before SE administration was used as baseline. All data are presented as changes relative to their respective baseline, which was defined as $100 \%$. Measurements were performed with 3 rats in each group.

To elucidate the involvement of afferent autonomic nerve activity, the subdiaphragmatic vagotomy model was also employed. The animals were vagotomized after cannulation, and the muscle SNA was recorded as described above.

\section{Measurement of skeletal muscle blood flow}

Muscle blood flow was measured using the laser Doppler method as described previously (Kobayashi et al. 2000, Horii et al. 2015). In brief, under urethane anesthesia, the vastus medialis of the quadriceps femoris muscle was exposed. The probe (tip diameter, $1 \mathrm{~cm}$ ) of a laser flowmeter (ALF21; Advance Co., Tokyo, Japan) was fixed on the muscle surface with surgical tape. After stabilization of blood flow for $1.5 \mathrm{~h}$, either vehicle $(0.5-\mathrm{ml}$ olive oil, control group) or SE $(20 \mathrm{mg} / \mathrm{kg}$ in $0.5-\mathrm{ml}$ olive oil) was administered to the rat via the stomach cannula. Blood flow was then recorded for $60 \mathrm{~min}$.

To elucidate the involvement of efferent autonomic nerve activity, the $\beta 2$-adrenergic receptor inhibitor, butoxamine, was administered. After blood flow stabilization for $1.5 \mathrm{~h}$, either saline $(0.1 \mathrm{ml}$, control group) or butoxamine $(0.3 \mathrm{mg}$ in $0.1-\mathrm{ml}$ saline) was injected via the cervical vein cannula. After $30 \mathrm{~min}$, either vehicle $(0.5-\mathrm{ml}$ olive oil, control group) or SE (20 $\mathrm{mg} / \mathrm{kg}$ in $0.5-\mathrm{ml}$ olive oil) was intragastrically administered, and the blood flow measured for $60 \mathrm{~min}$.

Data were sampled with a Power-Lab analog-todigital converter (ADInstruments, Sydney, Australia). The skeletal muscle blood flow was averaged over $5 \mathrm{~min}$ intervals. Similar to the SNA data, the averaged signal $5 \mathrm{~min}$ before SE administration was used as baseline and all data are presented as changes relative to their baseline. Measurements were performed with 5 rats in each group.

\section{Statistical analysis}

All data are expressed as the mean \pm standard error of the mean (SEM). Statistical significance was determined using repeated measures analysis of variance (ANOVA). In the case of a 4-group comparison, following ANOVA, the Tukey's post hoc test was performed for the value at $60 \mathrm{~min}$ after administration. The Mann-Whitney $U$ test was used to examine the statistical significance between the absolute baseline values of each group for each parameter. $P<0.05$ was defined as statistically significant. Statistical analyses were performed using IBM SPSS statistics 25 software (IBM, NY, USA).

\section{Results}

\section{SE increases skeletal muscle SNA}

The changes in the skeletal muscle SNA are shown in Fig. 1. The absolute baseline values were $255 \pm 12$ spikes $/ 5 \mathrm{~s}$ in the control group, $301 \pm 58$ spikes $/ 5 \mathrm{~s}$ in the $2-\mathrm{mg} / \mathrm{kg}$ SE group (Fig. 1A), $272 \pm 17$ spikes $/ 5 \mathrm{~s}$ in the second control group and $252 \pm 26$ spikes $/ 5 \mathrm{~s}$ in the $20-\mathrm{mg} / \mathrm{kg} \mathrm{SE}$ group (Fig. 1B). There were no significant differences in the absolute values at baseline between the SE groups and their corresponding controls. SNA measured at $60 \mathrm{~min}$ was increased by $45.2 \%$ and $66.1 \%$ relative to baseline for the $2-\mathrm{mg} / \mathrm{kg}$ and $20-\mathrm{mg} / \mathrm{kg}$ SE groups, respectively (Fig. 1D, E). In subsequent experiments, we used $20-\mathrm{mg} / \mathrm{kg}$ SE because it was most effective at increasing SNA.

\section{Subdiaphragmatic vagotomy abolished SE-induced increase in muscle SNA}

The subdiaphragmatic vagotomy was utilized to examine whether the sympathomimetic activity of SE depended on afferent autonomic nerve activity. A sham operation did not affect SNA (data not shown). In the vagotomy group, neither vehicle nor SE significantly changed skeletal muscle SNA (Fig. 1F), indicating this procedure completely abolished the increase in SNA typically observed after SE administration. The absolute values at baseline showed no differences (262 \pm 16 spikes $/ 5 \mathrm{~s}$ in the control group and $281 \pm 22$ spikes $/ 5 \mathrm{~s}$ in the SE group; Fig. 1C).

\section{SE increases blood flow in skeletal muscles}

The averaged data for skeletal muscle blood flow are presented in Fig. 2. The absolute values at baseline were $33.3 \pm 4.7 \mathrm{ml} / \mathrm{min} / 100 \mathrm{~g}$ tissue in the control group and $39.6 \pm 8.5 \mathrm{ml} / \mathrm{min} / 100 \mathrm{~g}$ tissue in the SE group, with no significant difference between the two groups. SE significantly increased skeletal muscle blood flow up to $39.6 \%$ after $55 \mathrm{~min}$. 
A)

control

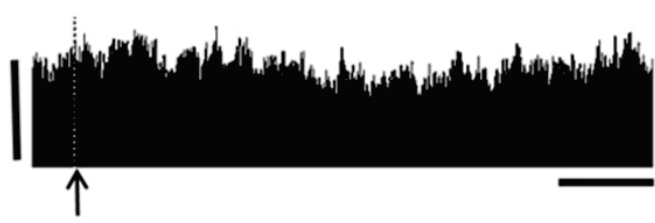

$\mathrm{SE}(2 \mathrm{mg} / \mathrm{kg})$

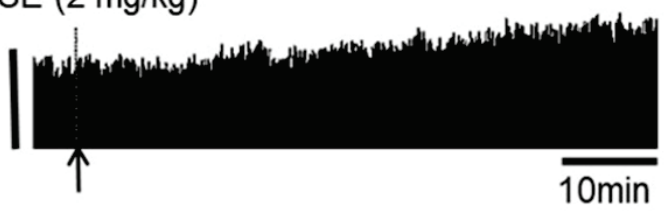

B)
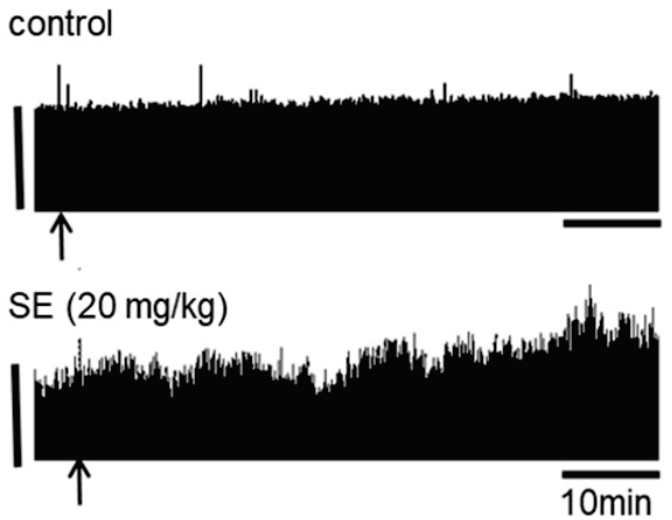

C)

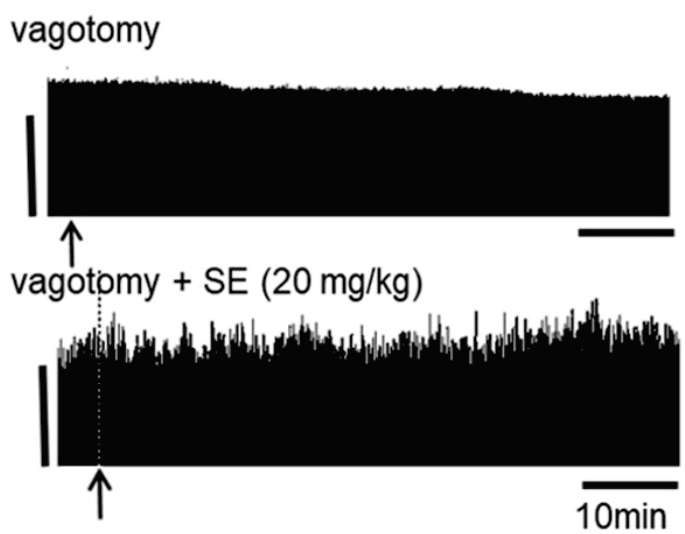

D)

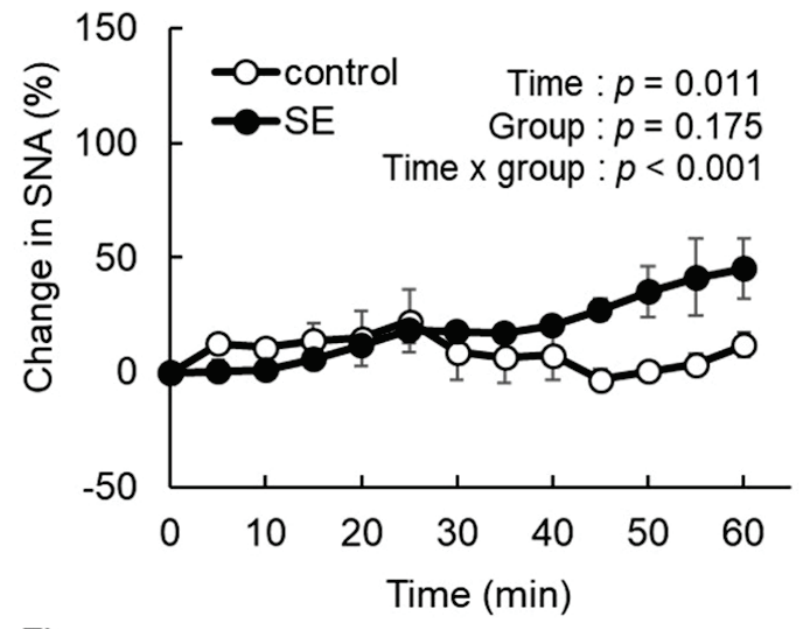

E)

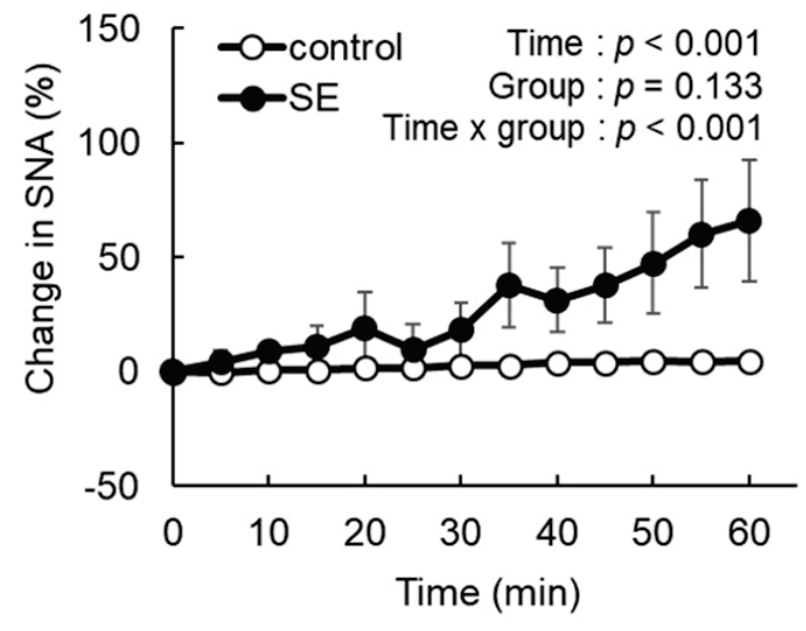

F)

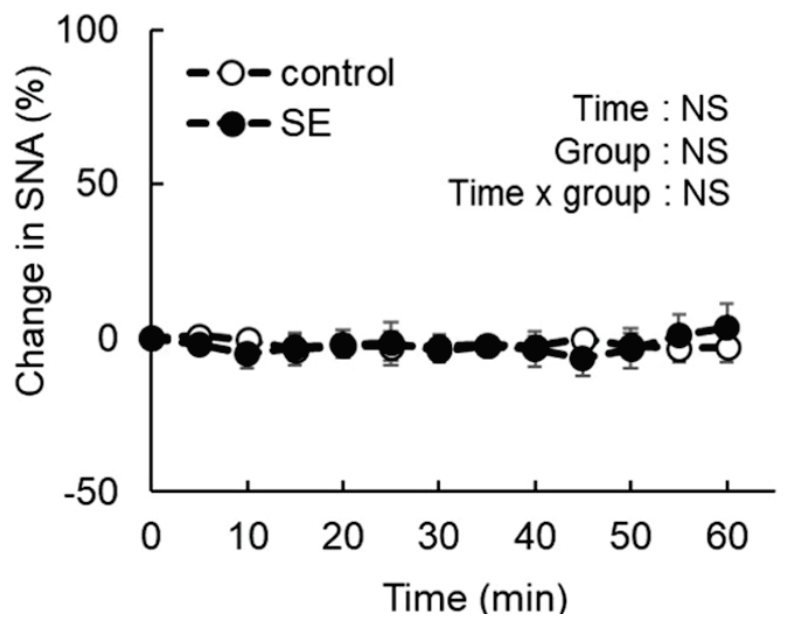

Fig. 1. Effect of sesame lignans (SE) on the sympathetic nerve activity (SNA) in skeletal muscles of urethane-anesthetized rats. Rats were intragastrically administrated SE (2 or $20 \mathrm{mg} / \mathrm{kg}$ ) after sympathetic nerves innervating skeletal muscle were stabilized. The muscle SNA activity was recorded for $60 \mathrm{~min}$ after administration. (A-C) Representative images of changes in neural activity. Arrows indicate the time of administration (vehicle or SE). Vertical scale bars indicate neural discharge rates of $200 \mathrm{spikes} / 5 \mathrm{~s}$. (D) Changes in muscle SNA after administration of vehicle or SE $(2 \mathrm{mg} / \mathrm{kg})$. (E) Changes in muscle SNA after administration of vehicle or SE $(20 \mathrm{mg} / \mathrm{kg})$. (F) Changes in muscle SNA in rats subjected to subdiaphragmatic vagotomy after administration of vehicle or SE $(20 \mathrm{mg} / \mathrm{kg})$. Values are presented as the mean \pm SEM $(n=3)$. Comparison between two groups was performed by repeated measures analysis of variance (ANOVA). NS, not significant. 


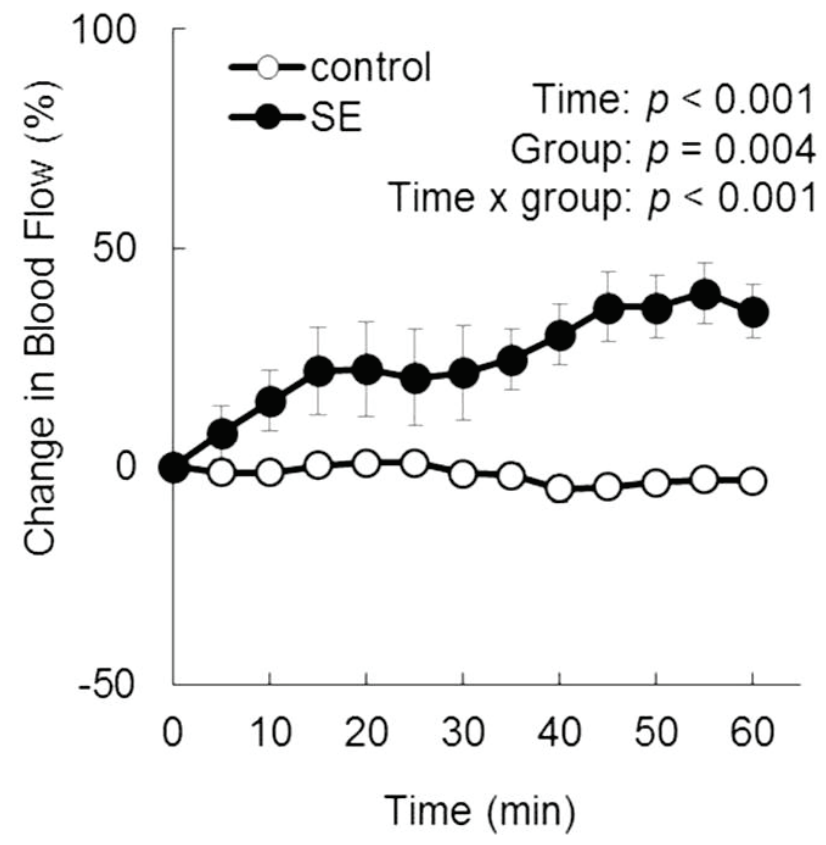

Fig. 2. Effect of SE on the muscle blood flow in urethaneanesthetized rats. Rats were intragastrically administrated vehicle or SE $(20 \mathrm{mg} / \mathrm{kg})$ after the muscle blood flow was stabilized. Muscle blood flow ( $\mathrm{ml} / \mathrm{min} / 100 \mathrm{~g}$ of tissue) was measured for 60 min. Values are presented as the mean $\pm \operatorname{SEM}(n=5)$. Comparison between two groups was performed by repeated measures ANOVA.

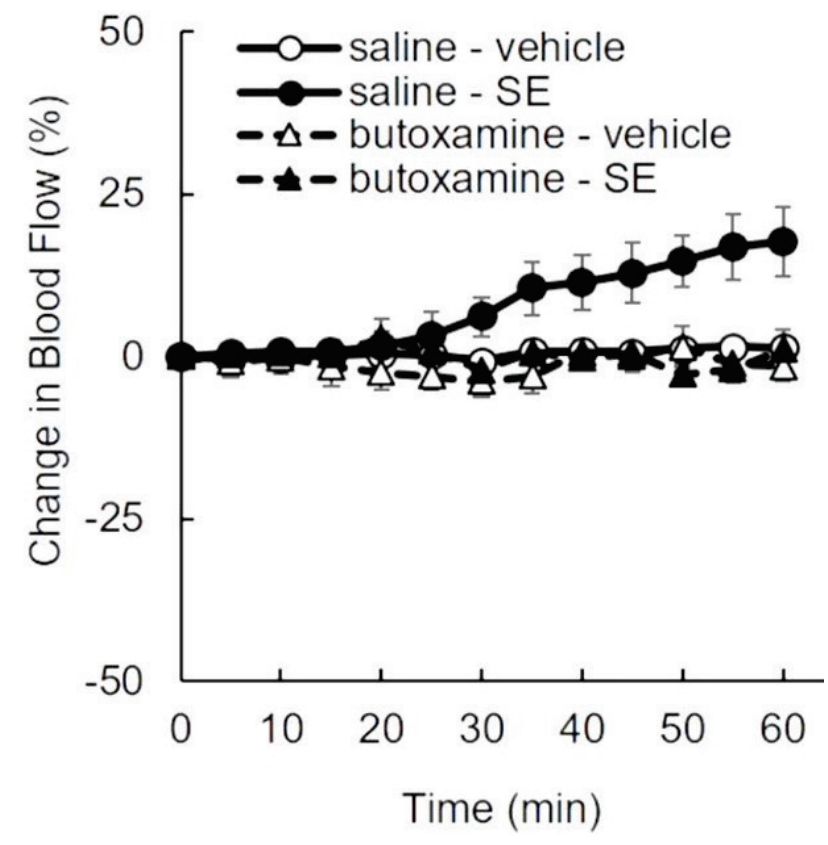

Fig. 3. Effect of $\beta 2$-adrenergic receptor inhibition on SE-induced increase in muscle blood flow. Urethane-anesthetized rats intravenously received butoxamine hydrochloride $(0.3 \mathrm{mg} / 0.1 \mathrm{ml}$ in saline) or physiological saline $30 \mathrm{~min}$ before gastric administration of vehicle or SE $(20 \mathrm{mg} / \mathrm{kg})$. Muscle blood flow $(\mathrm{ml} / \mathrm{min} / 100 \mathrm{~g}$ of tissue) was measured for $60 \mathrm{~min}$. Values are presented as the mean \pm SEM $(n=5)$. Comparison between groups was performed by repeated measures ANOVA. Then the values at $60 \mathrm{~min}$ after administration were statistically analyzed by the Tukey's post hoc test. * $p<0.05$.
B2-adrenergic receptor inhibitor abolished SE-induced increase in muscle blood flow

Pre-treatment with butoxamine was used to evaluate the involvement of efferent autonomic nerve activity in the SE-induced increase in skeletal muscle blood flow. No change in blood flow was observed following the administration of saline or butoxamine alone. Similar to the previous experiment (Fig. 2), blood flow in the saline $+\mathrm{SE}$ group gradually increased over time and reached a value of $17.6 \%$ at 60 min after SE administration. However, pre-treatment with butoxamine completely prevented the SE-induced increase in blood flow (Fig. 3). The baseline values of each group were $90.3 \pm 5.2 \mathrm{ml} / \mathrm{min} / 100 \mathrm{~g}$ tissue (saline + vehicle), $91.7 \pm 6.8 \mathrm{ml} / \mathrm{min} / 100 \mathrm{~g}$ tissue (butoxamine + vehicle), $83.1 \pm 5.1 \mathrm{ml} / \mathrm{min} / 100 \mathrm{~g}$ tissue (saline $+\mathrm{SE}$ ), and $90.7 \pm 9.3 \mathrm{ml} / \mathrm{min} / 100 \mathrm{~g}$ tissue (butoxamine $+\mathrm{SE}$ ), with no significant differences among these groups. The difference in blood flow at 60 min after administration was statistically significant in the saline + SE group compared all the other groups.

\section{Discussion}

The autonomic nervous system is known to be involved in the control of blood flow (Ganong 2005, Marieb and Hoehn 2008). This study revealed that the intragastric administration of sesame lignans significantly increases SNA in skeletal muscles and that this effect could be completely abolished by subdiaphragmatic vagotomy. Moreover, sesame lignans significantly elevated skeletal muscle blood flow, an effect that was completely abolished by pre-treatment with the $\beta 2$-adrenergic receptor inhibitor, butoxamine. These results suggest that the intragastric administration of sesame lignans increased skeletal muscle SNA via the afferent vagal nerve signals, likely originating at the stomach or intestine, and caused dilation of arterial blood vessels, resulting in increased muscular blood flow. This is the first study providing direct evidence that sesame lignans affect the autonomic nervous system.

In the present study, skeletal muscle SNA started to increase within $5 \mathrm{~min}$ of the administration of sesame lignans, suggesting activity within the gastrointestinal tract. Subdiaphragmatic vagotomy results also indicated that nerves below the diaphragm respond either directly or indirectly to sesame lignans.

Several reports have demonstrated that muscle fatigue is likely to occur if blood flow to muscles is 
restricted (Karabulut et al. 2010). Sugaya et al. (2011) have shown that a $43 \%$ decrease in blood flow of the lower limbs results in a significant increase in inorganic phosphate, thus promoting muscle fatigue. Conversely, an increase in blood flow may contribute to a reduction in muscle fatigue and result in the alleviation of the subjective feeling of fatigue. Sesame lignans were shown to increase skeletal muscle blood flow by up to $40 \%$, which is similar to the increase reported using L-carnosine (Horii et al. 2015). Therefore, it is likely that this increase would promote the excretion of fatigueinducing substances from skeletal muscles. Intake of sesame lignans has been reported to improved reduced exercise capacity in diabetic model mice (Takada et al. 2015) and alleviate subjective feeling of fatigue in humans (Takemoto et al. 2015). It is also known that the autonomic nervous system response is blunted by fatigue (Stewart 2000, Mizuno et al. 2011). The mechanism behind these anti-fatigue effects may involve autonomic nervous system modulation as shown in the current study.

This study has provided experimental evidence that a single dose of sesame lignans can increase blood flow in the muscle. Similarly, a single period of exercise transiently induces increased heart rate and blood pressure, accompanied by changes in blood flow. These changes impose shear stress on vascular endothelial cells and trigger changes in gene expression. It is thought that when these stimuli are repeated by making exercise habitual, blood vessel remodeling and neovascularization occur, ultimately leading to a decrease in blood pressure (Hudlicka and Brown 2009). Therefore, a similar beneficial effect on the vascular system may be induced by repeated intake of sesame lignans.

Aging is also known to result in the decline and imbalance of the autonomic nerve activity. Bretherton et al. (2019) have reported that stimulating the vagal nerve improves autonomic function and some aspects of quality of life, mood, and sleep in individuals aged 55 years or above. Therefore, sesame lignans may be effective against a decline in the autonomic nerve activity with age.

All experiments were performed under anesthesia in order to accurately obtain SNA and blood flow measurements from the skeletal muscles of rats. Further studies are needed to clarify the effects of sesame lignans on skeletal muscle blood flow, skeletal muscle and other organ SNA under physiological conditions in animals and humans.

In conclusion, sesame lignans can increase the blood flow of skeletal muscle, possibly by exciting sympathetic nerve activity through the afferent vagal nerve. We propose that this could be one of the mechanisms responsible for the physiological effects of sesame lignans.

\section{Conflict of Interest}

K.E., I.Y., D.T., Y.O., T.R. and H.S. are employees of Suntory Wellness, Ltd., which is a manufacturer of foods that contain sesame lignans. This study was funded by Suntory Wellness, Ltd.

\section{Acknowledgements}

We thank Dr. Y Kitagawa (Suntory Wellness, Ltd.) for useful discussions and proofreading of the manuscript.

\section{References}

AMANO M, OIDA E, MORITANI T: Age-associated alteration of sympatho-vagal balance in a female population assessed through the tone-entropy analysis. Eur J Appl Physiol 94: 602-610, 2005. https://doi.org/10.1007/s00421-005-1364-x

AMANO M, OIDA E, MORITANI T: A comparative scale of autonomic function with age through the tone-entropy analysis on heart period variation. Eur J Appl Physiol 98: 276-283, 2006. https://doi.org/10.1007/s00421-006$\underline{0275-9}$

BEPPU Y, IZUMO T, HORII Y, SHEN J, FUJISAKI Y, NAKASHIMA T, TSURUOKA N, NAGAI K: Effects of culture supernatant from Lactobacillus pentosus strain S-PT84 on autonomic nerve activity in rats. In Vivo 26: 355-359, 2012.

BRETHERTON B, ATKINSON L, MURRAY A, CLANCY J, DEUCHARS S, DEUCHARS J: Effects of transcutaneous vagus nerve stimulation in individuals aged 55 years or above: potential benefits of daily stimulation. Aging (Albany Y): 102074, 2019. https://doi.org/10.18632/aging.102074

FUKUDA Y, NAGATA M, OSAWA T, NAMIKI M: Contribution of lignan analogues to antioxidative activity of refined unroasted sesame seed oil. J Am Oil Chem Soc 63: 1027-1031, 1986. https://doi.org/10.1007/BF02673792 
GANONG WF: Review of Medical Physiology LANGE Basic Science. McGraw-Hill, New York, 2005.

HONG L, YI W, LIANGLIANG C, JUNCHENG H, QIN W, XIAOXIANG Z: Hypoglycaemic and hypolipidaemic activities of sesamin from sesame meal and its ability to ameliorate insulin resistance in KK-Ay mice. J Sci Food Agric 93: 1833-1838, 2013. https://doi.org/10.1002/jsfa.5974

HORII Y, FUJISAKI Y, FUYUKI R, NAGAI K: L-Carnosine's dose-dependent effects on muscle sympathetic nerves and blood flow. Neurosci Lett 591: 144-148, 2015. https://doi.org/10.1016/j.neulet.2015.02.044

HUDLICKA O, BROWN M: Adaptation of skeletal muscle microvasculature to increased or decreased blood flow: role of shear stress, nitric oxide and vascular endothelial growth factor. J Vasc Res 46: 504-512, 2009. https://doi.org/10.1159/000226127

IDE T, ONO Y, KAWASHIMA H, KISO Y: Interrelated effects of dihomo- $\gamma$-linolenic and arachidonic acids, and sesamin on hepatic fatty acid synthesis and oxidation in rats. Br J Nutr 108: 1980-1993, 2012. https://doi.org/10.1017/S0007114512000141

IKEDA T, NISHIJIMA Y, SHIBATA H, KISO Y, OHNUKI K, FUSHIKI T, MORITANI T: Protective effect of sesamin administration on exercise-induced lipid peroxidation. Int J Sports Med 24: 530-534, 2003. https://doi.org/10.1055/s-2003-42010

KAMIO N, SUZUKI T, WATANABE Y, SUHARA Y, OSAKABE N: A single oral dose of flavan-3-ols enhances energy expenditure by sympathetic nerve stimulation in mice. Free Radic Biol Med 91: 256-263, 2016. https://doi.org/10.1016/j.freeradbiomed.2015.12.030

KARABULUT M, CRAMER JT, ABE T, SATO Y: Neuromuscular fatigue following low-intensity dynamic exercise wirth externally applied vascular restriction. J Electromyogr Kinesiol 20: 440-447, 2010. https://doi.org/10.1016/j.jelekin.2009.06.005

KISO Y: Antioxidative roles of sesamin, a functional lignan in sesame seed, and its effect on lipid- and alcoholmetabolism in the liver: a DNA microarray study. Biofactors 21: 191-196, 2004. https://doi.org/10.1002/biof.552210139

KITA S, MATSUMURA Y, MORIMOTO S, AKIMOTO K, FURUYA M, OKA N, TANAKA T: Antihypertensive effect of sesamin. II. Protection against two-kidney, one-clip renal hypertension and cardiovascular hypertrophy. Biol Pharm Bull 18: 1283-1285, 1995. https://doi.org/10.1248/bpb.18.1283

KOBAYASHI K, KOBAYASHI Y, HASHIDA-OKUMURA A, IIMORI S, NAGAI K, NAKASHIMA H: Increase in peripheral blood flow due to extraocular direct irradiation of visible light in rats. Am J Physiol Heart Circ Physiol 279: H1141-H1146, 2000. https://doi.org/10.1152/ajpheart.2000.279.3.H1141

MARIEB EN, HOEHN K: Anatomy \& Physiology, Third editon, Pearson/Benjamin Commings, San Francisco, 2008, pp 524-527.

MATSUMURA Y, KITA S, MORIMOTO S, AKIMOTO K, FURUYA M, OKA N, TANAKA T: Antihypertensive effect of sesamin. I. Protection against deoxycorticosterone acetate-salt-induced hypertension and cardiovascular hypertrophy. Biol Pharm Bull 18: 1016-1019, 1995. https://doi.org/10.1248/bpb.18.1016

MIYAWAKI T, AONO H, TOYODA-ONO Y, MAEDA H, KISO Y, MORIYAMA K: Antihypertensive effects of sesamin in humans. J Nutr Sci Vitaminol 55: 87-91, 2009. https://doi.org/10.3177/jnsv.55.87

MIZUNO K, TANAKA M, YAMAGUTI K, KAJIMOTO O, KURATSUNE H, WATANABE Y: Mental fatigue caused by prolonged cognitive load associated with sympathetic hyperactivity. Behav Brain Funct 7: 17, 2011. https://doi.org/10.1186/1744-9081-7-17

NAGAI K, HORII Y, FUJISAKI Y, FUYUKI R, MISONOU Y: Effects of olfactory stimulation with scents of grapefruit and lavender essential oils on the skeletal muscle sympathetic nerve and muscle blood flow in rats. Flavour Fragr J 33: 135-143, 2018. https://doi.org/10.1002/ffj.3417

NAKAI M, HARADA M, NAKAHARA K, AKIMOTO K, SHIBATA H, MIKI W, KISO Y: Novel antioxidative metabolites in rat liver with ingested sesamin. J Agric Food Chem 51: 1666-1670, 2003. https://doi.org/10.1021/jf0258961

OSAKABE N, TERAO J: Possible mechanisms of postprandial physiological alterations following flavan 3-ol ingestion. Nutr Rev 76: 174-186, 2018. https://doi.org/10.1093/nutrit/nux070 
STEWART JM: Autonomic nervous system dysfunction in adolescents with postural orthostatic tachycardia syndrome and chronic fatigue syndrome is characterized by attenuated vagal baroreflex and potentiated sympathetic vasomotion. Pediatr Res 48: 218-226, 2000. https://doi.org/10.1203/00006450-200008000-00016

SUGAYA M, YASUDA T, SUGA T, OKITA K, ABE T: Change in intramuscular inorganic phosphate during multiple sets of blood flow-restricted low-intensity exercise: Change in intramuscular metabolism during BFR exercise. Clin Physiol Funct Imaging 31: 411-413, 2011. https://doi.org/10.1111/j.1475-097X.2011.01033.x

TAKADA S, KINUGAWA S, MATSUSHITA S, TAKEMOTO D, FURIHATA T, MIZUSHIMA W, FUKUSHIMA A, YOKOTA T, ONO Y, SHIBATA H, OKITA K, TSUTSUI H: Sesamin prevents decline in exercise capacity and impairment of skeletal muscle mitochondrial function in mice with high-fat diet-induced diabetes. Exp Physiol 100: 1319-1330, 2015. https://doi.org/10.1113/EP085251

TAKEMOTO D, YASUTAKE Y, TOMIMORI N, ONO Y, SHIBATA H, HAYASHI J: Sesame lignans and vitamin E supplementation improve subjective statuses and anti-oxidative capacity in healthy humans with feelings of daily fatigue. Glob J Health Sci 7: 1-10, 2015. https://doi.org/10.5539/gjhs.v7n6p1

TANIDA M, NIIJIMA A, FUKUDA Y, SAWAI H, TSURUOKA N, SHEN J, YAMADA S, KISO Y, NAGAI K: Dose-dependent effects of L-carnosine on the renal sympathetic nerve and blood pressure in urethaneanesthetized rats. Am J Physiol Regul Integr Comp Physiol 288: R447-R455, 2005. https://doi.org/10.1152/ajpregu.00275.2004

YUKISHITA T, LEE K, KIM S, YUMOTO Y, KOBAYASHI A, SHIRASAWA T, KOBAYASHI H: Age and sex-dependent alterations in heart rate variability. Anti-Aging Medicine 7: 94-99, 2010. https://doi.org/10.3793/jaam.7.94 